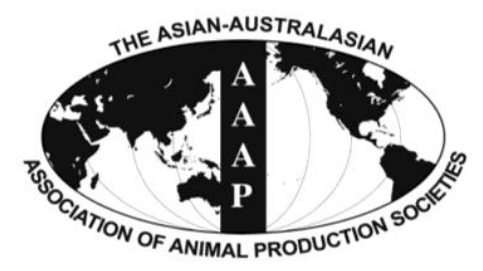

Asian-Aust. J. Anim. Sci.

Vol. 26, No. 2 : 247-252 February 2013

http://dx.doi.org/10.5713/ajas.2012.12299

www.ajas.info

pISSN 1011-2367 elSSN 1976-5517

\title{
Effect of Supplementing Organic Selenium on Performance, Carcass Traits, Oxidative Parameters and Immune Responses in Commercial Broiler Chickens
}

\author{
Savaram Venkata Rama Rao*, Bhukya Prakash, Mantena Venkata Laxmi Narasimha Raju, \\ Arun Kumar Panda, Saharia Poonam and Orugonda Krishna Murthy \\ Project Directorate on Poultry, Rajendranagar, Hyderabad 500 030, India
}

\begin{abstract}
An experiment was conducted to determine the effect of supplementing various concentrations $(0,100,200,300$, or 400 $\mu \mathrm{g} / \mathrm{kg}$ diet) of organic Se on growth performance, carcass traits, oxidative stress, and immune responses in commercial broiler chickens reared in open-sided poultry house under tropical climatic conditions. Each diet was fed ad libitum to eight replicates consisting of six birds in each pen from 1 to $42 \mathrm{~d}$ of age. Body weight gain and feed efficiency, and relative weight of liver, abdominal fat and ready to cook yields were not affected ( $>0.05$ ) by organic Se supplementation to broiler diets. Lipid peroxidation in plasma decreased, while activities of glutathione peroxidase and glutathione reductase in plasma increased $(\mathrm{p}<0.01)$ linearly with Se concentration in diet. The ratios between heterophyls and lymphocytes and relative weight of lymphoid organs (bursa, spleen, and thymus), and antibody production to Newcastle disease vaccination were not affected $(p>0.05)$ by Se supplementation to broiler diets. However, the cellmediated immunity (lymphocyte proliferation ratio) increased $(\mathrm{p}<0.01)$ linearly with dietary Se concentration. The results of the present study indicate that the supplementation of Se did not influence body weight and feed efficiency. However, supplementation of Se increased antioxidant status and lymphocyte proliferation in broiler chickens. (Key Words: Broiler Chicken, Immunity, Organic Selenium, Oxidative Stress, Performance)
\end{abstract}

\section{INTRODUCTION}

Genetic selection for higher growth rate, and providing balanced diet and superior health care measures led to a higher body weight in commercial broilers. The birds that are being reared in open-sided poultry houses may lead to stress due to constant dynamic variations in temperature and humidity in the environment, which causes adverse effects on performance (Niu et al., 2009), meat quality and immune responses (Thompson and Scott, 1970). Further, heat causes a major stressor for chicken due to their high metabolic rate, and body temperature and lack of sweat glands (Sahin and Kucuk, 2003). High environmental temperature in the tropical countries causes heavy financial losses to poultry due to reduced feed intake and decreasing feed conversion efficiency (Panda et al., 2008). However, theses adversities in the tropics can be minimized by feeding diet

* Corresponding Author: Savaram Venkata Rama Rao. Tel: +91-4024015651, Fax: +91-4024017002, E-mail: svramarao1 @ gmail.com

Submitted May 29, 2012; Accepted Jul. 3, 2012; Revised Aug. 31, 2012 supplemented with organic selenium (Se).

Se is a trace mineral that is essential to keep good health for animals and humans. Deficiency of Se results in exudative diathesis and pancreatic degeneration (Toghyani et al., 2008), and it plays an important role in immune function and production of immunoglobulin (Spallholz et al., 1973). Supplementation of Se in chicken diet increases antibody titers to Newcastle disease (ND) (Hegazy and Adachi, 2000). Further, Se influences immune responses through its incorporation into selenoproteins such as the amino acid selenocysteine (Hoffmann, 2007).

The biological systems are continuously influenced to free radicals and reactive oxygen species (ROS), which are produced as a part of the normal cell metabolism (Tappel and Tappel, 2004). Furthermore, in a several physiological and pathological states, excess amounts of ROS are generated (Fridivich, 1978), which damages the cell phospholipid membranes and other macromolecules (Wiseman and Halliwell, 1996). Utilization of appropriate antioxidants will help the biological system by scavenging reactive oxygen, which intern reduces lipid peroxidation 
(LP) and increase activity of antioxidant defense system (Nunes et al., 2005).

The ideal Se concentration in the diet is essential for the normal development and functioning of the immune system (Koski and Marilyn, 2003) and for maintaining the systemic defense in broilers reared in tropics. However, information about the beneficial effects of supplementation of Se in maize and soybean meal-based diets on performance of broiler reared in tropics is scanty. Therefore, an experiment was conducted to study the effects of supplementing Se on performance, slaughter parameters, stress indices, and immune responses in commercial broilers.

\section{MATERIALS AND METHODS}

\section{Experimental birds, management, and diets}

Day-old commercial female broiler chicks $(n=240)$ were distributed randomly into eight replicates of five treatments with six chicks in each replicate (pen). On day one, chicks were wing banded and housed in wire-floored stainless steel battery brooders. The brooder temperature was maintained at $35 \pm 0.5^{\circ} \mathrm{C}$ until $7 \mathrm{~d}$ of age and gradually decreased to $27^{\circ} \mathrm{C}$ by $21 \mathrm{~d}$ of age, after which, chicks were maintained at room temperature $\left(20\right.$ to $\left.27^{\circ} \mathrm{C}\right)$. Birds were vaccinated against Newcastle (7th and 28th d) and infectious bursal diseases (15th d) as per the standard vaccination schedule. The experimental protocol was approved by the institute animal ethics committee.

Maize and soybean meal-based diets were prepared to contain 2,944, 3,049 and 3,150 kcal ME/kg during the prestarter ( 1 to $11 \mathrm{~d})$, starter (12 to $21 \mathrm{~d}$ ), and finisher ( $>22 \mathrm{~d}$ of age) phases, with respective crude protein contents of 23 , 21 , and $19 \mathrm{~g} / 100 \mathrm{~g}$ feed (Table 1 ). The maize and soybean meal were analyzed for amino acid concentrations (Llames and Fontaine, 1994). The analyzed amino acid composition was utilized for formulating the experimental diets. Further, the diets were supplemented with organic Se (MinPlex Selenium, Bentoli AgriNutrition, Homestead, Florida, USA) to arrive five graded concentrations in diet I (basal diet without organic Se); diet II (diet I+organic Se at $100 \mu \mathrm{g} / \mathrm{kg}$ diet); diet III (diet I+organic Se at $200 \mu \mathrm{g} / \mathrm{kg}$ diet); diet IV (diet I+organic Se at $300 \mu \mathrm{g} / \mathrm{kg}$ diet); diet V (diet I+organic Se at $400 \mu \mathrm{g} / \mathrm{kg}$ diet), and each diet was allotted at random to eight replicates and fed ad libitum from 1 to $42 \mathrm{~d}$ of age. The weighed amount of organic Se was incorporated in the premix for various diets in order to attain the desired concentration and finally the premix was thoroughly mixed with the respective diets using stainless steel double cone blenders with $300 \mathrm{rpm}$ for $3 \mathrm{~min}$.

\section{Productive performance and carcass parameters}

Body weight and feed intake were recorded at 21 and 42 $\mathrm{d}$ of age, and feed efficiency per pen was calculated as body
Table 1. Ingredient and nutrient content of the basal diets

\begin{tabular}{|c|c|c|c|}
\hline & Pre-starter & Starter & Finisher \\
\hline & \multicolumn{3}{|c|}{ Age (d) } \\
\hline & $1-11$ & $12-21$ & $22-42$ \\
\hline \multicolumn{4}{|l|}{ Ingredients (\%) } \\
\hline Maize & 50.1 & 54.7 & 60.1 \\
\hline Soybean meal, $46 \% \mathrm{CP}$ & 42.2 & 36.7 & 31.1 \\
\hline Sunflower oil & 3.58 & 4.36 & 4.85 \\
\hline Common salt & 0.35 & 0.35 & 0.35 \\
\hline Sodium bicarbonate & 0.1 & 0.1 & 0.1 \\
\hline Dicalcium phosphate & 1.93 & 1.97 & 1.71 \\
\hline Oyster shell grit & 0.97 & 1.01 & 0.93 \\
\hline DL-methionine & 0.17 & 0.15 & 0.13 \\
\hline L-lysine $\mathrm{HCl}$ & 0 & 0.042 & 0.077 \\
\hline Premix $^{\mathrm{a}}$ & 0.55 & 0.55 & 0.55 \\
\hline \multicolumn{4}{|l|}{ Nutrient content (dry matter basis) } \\
\hline Metabolizable energy ${ }^{\mathrm{b}}(\mathrm{kcal} / \mathrm{g})$ & 2.94 & 3.05 & 3.15 \\
\hline Crude protein ${ }^{c}(\%)$ & 23.0 & 21.0 & 19.0 \\
\hline $\operatorname{Lysine}^{\mathrm{d}}(\%)$ & 1.30 & 1.19 & 1.07 \\
\hline Methionine $^{\mathrm{d}}(\%)$ & 0.51 & 0.46 & 0.42 \\
\hline Calcium $^{\mathrm{b}}(\%)$ & 0.89 & 0.88 & 0.78 \\
\hline Non-phytate phosphorus ${ }^{\mathrm{b}}(\%)$ & 0.45 & 0.45 & 0.40 \\
\hline
\end{tabular}

Diet I (basal diet without organic Se); Diet II (Diet I+organic Se at 100 $\mu \mathrm{g} / \mathrm{kg}$ diet); Diet III (Diet I+organic Se at $200 \mu \mathrm{g} / \mathrm{kg}$ diet); Diet IV (Diet I+organic Se at $300 \mu \mathrm{g} / \mathrm{kg}$ diet); Diet V (Diet I+ organic Se at $400 \mu \mathrm{g} / \mathrm{kg}$ diet)

${ }^{a}$ Premix provided (in milligrams/kilogram diet): thiamin 1; pyridoxine, 2; cyanocobalamine, 0.01; niacin, 15; pantothenic acid, 10; $\alpha$-tocopherol, $10 \mathrm{IU}$; riboflavin, 10; biotin, 0.08; menadione, 2; retinol acetate, 2.75; cholecalciferol, 0.03; choline, 650; copper, 8; iron, 45; manganese, 80; zinc, 60 ; selenium, 0.18 ; monensin sodium, 50 ; hydrated sodium calcium alumino silicates, 800 .

${ }^{\mathrm{b}}$ Calculated values. ${ }^{\mathrm{c}}$ Analyzed values.

${ }^{\mathrm{d}}$ Calculated based on analyzed ingredient composition.

weight gain per unit feed intake.

At $42 \mathrm{~d}$ of age, eight birds from each treatment weighing near to the mean body weight $( \pm 5 \%)$ of the respective group were selected and removed from feed for $12 \mathrm{~h}$ to record body weight loss during pre-slaughter holding period. The birds were slaughtered by cervical dislocation to study carcass traits. Ready to cook yield (including giblet) and relative weight of breast, abdominal fat, and liver were recorded and expressed as grams per kilogram pre-slaughter live body mass of the respective bird.

\section{Stress parameters}

Stress responses in terms of LP, activities of certain antioxidant enzymes, and HL ratio in peripheral blood smears were studied. Approximately $4 \mathrm{ml}$ of blood was drawn from the brachial vein of eight birds per treatment on 35 th $\mathrm{d}$ of age into a centrifuge tube containing citrate buffer (citrate $0.8 \mathrm{~g} / 100 \mathrm{ml}$ and $1.5 \mathrm{ml} / 10 \mathrm{ml}$ blood) for erythrocyte separation and enzyme estimation. Blood samples were centrifuged at $500 \times g$ for $15 \mathrm{~min}$ at $4^{\circ} \mathrm{C}$ to 
separate the buffy coat and RBC pellet. The RBC were washed thrice with PBS ( $\mathrm{pH} 7.4)$. The RBC pellet was mixed with an equal volume of PBS, and then lysed using distilled water (RBC to distilled water, 1:20) and the same procedure was applied for quantifying the LP (Ohkawa et al., 1979), activity of RBCC (Berg Meyer, 1983). The degree of peroxidation was expressed as nanomoles malonyl dialdehyde (MDA)/milligram protein and the RBCC activity as units per gram of hemoglobulin, respectively. The hemolysate was also analyzed for the activities of GSH Rx (Cohen et al., 1970) and GSH Px (Paglia and Valantine, 1967), which were expressed as units/milliliter. At $42 \mathrm{~d}$ of age, blood smears (eight birds from each treatment) were prepared and stained with Giemsa, and 100 cells were counted to calculate HL ratio.

\section{Immune responses}

The effect of supplementing Se on humoral (ND virus) and cell-mediated (LPR) immune responses were studied. Blood samples were collected from one bird from each pen (eight birds from each treatment) on the 40th $\mathrm{d}$ of age to study the LPR and antibody titres against NDV.

\section{In vitro $\mathbf{L P R}$}

In vitro LPR was determined using the mitogen Concanavalin A (Con A) and determined as LPR between the proliferation of mitogen-stimulated and unstimulated cells. The LPR was measured using 3-(4, 5-dimethylthiazol2-yl)-2, 5-diphenyl tetrazolium bromide (MTT) salt (Bounous et al., 1992). At $40 \mathrm{~d}$ of age, approximately $2 \mathrm{ml}$ blood was collected from the brachial vein of the bird from each replicate and transferred to a centrifuge tube containing $5 \mathrm{mg}$ heparin disodium salt. The unclotted blood sample was layered gently over histopaque 1077 (Sigma, Mumbai, India) and centrifuged at $500 \times g$ for $20 \mathrm{~min}$ at $4{ }^{\circ} \mathrm{C}$. The cellular band at the interface was collected and transferred to another tube and washed three times with RPMI 1640 medium (AL 028A, Himedia, India). Numbers of viable cells were determined by using the trypan blue dye exclusion method, and cell concentration was adjusted to $1 \times 10^{7}$ cells/ml of RPMI 1640 medium. A sample of cells (105 purified lymphocytes) was used to measure lymphocyte proliferation by adding $10 \mu \mathrm{l}$ of suspension to each well of a 96-well flat bottom sterile tissue culture plate. Con A $(0.9 \mu \mathrm{g}$ in $150 \mu \mathrm{l} \mathrm{RPMI} /$ well $)$ was added to those cells to be stimulated. A similar volume of RPMI was added to the unstimulated cultures. The plate was incubated at $37^{\circ} \mathrm{C}$ and $5 \% \mathrm{CO}_{2}$ concentration for $69 \mathrm{~h}$ in a humid atmosphere, then $20 \mu \mathrm{MTT}(10 \mathrm{mg} / \mathrm{ml})$ was added to each well, and the plate was incubated for $3 \mathrm{~h}$. At $72 \mathrm{~h}, 100 \mu \mathrm{l}$ of $1 \mathrm{M} \mathrm{HCl}$-isopropanol (4\%) was added to each well and mixed thoroughly with a micropipette to dissolve the formazan crystals, which gave a deep purple color. The color intensity was measured in an enzyme-linked immunosorbent assay (ELISA) reader (V. 200.1, $\mu$ Quant; Biotek Instruments, Inc., USA) at $550 \mathrm{~nm}$. The LPR was calculated as (OD of Con A well-OD of without Con A well)/OD of unstimulated cells.

\section{Antibody titre to ND vaccine}

Broilers were vaccinated against ND by ocular route at the 7th and 28th d of age with Lsota strain (ND Lasota Vac500; Indivax Pvt., Ltd., Hyderabad, India). At $40 \mathrm{~d}$ of age, blood was collected and a serum was separated. Antibody titres against ND vaccine were measured with ELISA (966547; Synbiotics, San Diego, CA, USA).

\section{Statistical analysis}

The data were subjected to regression analysis considering the levels of Se as independent variable and various parameters (production, slaughter, stress, and immune responses) as dependent variables to know the relation (linear or nonlinear) between independent and dependant variables using SPSS software (SPSS Version 12; South Asia Pvt., Ltd., Bangaluru, India).

\section{RESULTS AND DISCUSSION}

\section{Productive performance and carcass traits}

The results of the present study showed the body weight gain, feed efficiency and slaughter traits (relative weight of ready to cook, giblet, liver, abdominal fat, spleen, bursa, breast muscle and thymus) were not affected ( $p>0.05)$ with Se supplementation (Table 2). The similar results have been reported, wherein Se supplementation revealed insignificant effects on body weight gain and feed efficiency (Downs et al., 2000; Choct et al., 2004; Payne and Southern, 2005; Perić et al., 2009) in broilers. On the contrary, it has been reported that the improved body weight and feed efficiency in chicken reared under the heat stress, when fed diet supplemented with Se (Christine et al., 2002; Niu et al., 2009; Ibrahim et al., 2011). Similarly, increased feed efficiency and body weight gain is reported in broilers chicken fed diet supplemented Se-enriched yeast (Krstic et al., 2012). The insignificant difference in body weight gain, feed efficiency and other slaughter parameters in the present study might be due to feeding the balanced diet with adequate nutritional practice (Lesson and Summer, 2001).

\section{Stress parameters}

LP decreased linearly $(\mathrm{p}<0.01)$ with each increment of Se in diet (Table 3). On the contrary, the activities of glutathione peroxidase (GSH Px), glutathione reductase (GSH Rx) and red blood cell (RBC) catalase (RBCC) increased linearly $(\mathrm{p}<0.01)$ with increase in $\mathrm{Se}$ concentration in diet. However, variation in concentration 
Table 2. Effect of dietary Se concentration $(\mu \mathrm{g} / \mathrm{kg})$ on various slaughter traits $(\mathrm{g} / \mathrm{kg}$ pre-slaughter live body eight) and performance in broiler chicks ( 1 to $42 \mathrm{~d}$ of age)

\begin{tabular}{|c|c|c|c|c|c|c|c|c|c|c|c|}
\hline $\begin{array}{l}\mathrm{Se} \\
(\mu \mathrm{g} / \mathrm{kg} \text { diet })\end{array}$ & $\begin{array}{c}\text { Body } \\
\text { weight }(\mathrm{g})\end{array}$ & FCR & $\begin{array}{c}\text { Holding } \\
\text { losses }\end{array}$ & RTC & Giblet & Liver & $\begin{array}{l}\text { Abdomin } \\
\text { al fat }\end{array}$ & Spleen & Bursa & $\begin{array}{l}\text { Brest } \\
\text { muscle }\end{array}$ & Thymus \\
\hline 0 & 2,295 & 1.756 & 79.4 & 690.5 & 43.17 & 22.43 & 16.18 & 1.369 & 1.242 & 163.2 & 2.129 \\
\hline 100 & 2,323 & 1.766 & 62.4 & 688.3 & 42.58 & 20.79 & 16.97 & 1.260 & 1.692 & 158.6 & 2.576 \\
\hline 200 & 2,336 & 1.736 & 49.6 & 685.6 & 42.31 & 21.02 & 16.93 & 1.317 & 1.537 & 161.2 & 2.768 \\
\hline 300 & 2,296 & 1.743 & 43.1 & 683.1 & 41.81 & 20.75 & 18.24 & 1.674 & 1.356 & 160.6 & 2.509 \\
\hline 400 & 2,257 & 1.781 & 28.9 & 686.3 & 41.48 & 19.45 & 14.20 & 1.080 & 1.474 & 160.9 & 2.442 \\
\hline SEM & 15.28 & 0.012 & 2.75 & 2.84 & 0.54 & 0.47 & 0.92 & 0.09 & 0.08 & 1.76 & 0.10 \\
\hline \multicolumn{12}{|l|}{$\mathrm{p}$ value } \\
\hline Linear & 0.345 & 0.770 & 0.01 & 0.50 & 0.28 & 0.06 & 0.68 & 0.801 & 0.82 & 0.85 & 0.46 \\
\hline Quadratic & 0.228 & 0.709 & 0.01 & 0.72 & 0.56 & 0.16 & 0.52 & 0.66 & 0.59 & 0.89 & 0.18 \\
\hline
\end{tabular}

Each mean represents the data from eight chicks.

RTC $=$ Ready to cook yield. SEM $=$ Standard error mean. $\mathrm{FCR}=$ Feed conversion ratio.

of Se in diet did not influence ( $\mathrm{p}>0.05)$ the heterophyl to lymphocyte (HL) ratio in broilers. It is well established that the LP, a process involved in degradation of structural components of cell membranes (Kuhn and Borchert, 2002; Georgieva et al., 2011) and ROS accumulation is known to induce LP and oxidative stress (Devi et al., 2000). Whereas, the RBCC, GSH Px and GSH Rx protects the biological cells from the adversities of ROS (Georgieva et al., 2011). GSH Px and GSH Rx are well known for catalyzing the reduction of hydrogen peroxide and organic hydroperoxides, thus protecting cells from oxidative damage (Papp et al., 2007). In the present study, decreased LP and increased activities of the above antioxidant enzymes suggest that $\mathrm{Se}$ supplementation progressively reduced oxidative stress with gradient increase in dietary Se concentration (Cave et al., 2006) in broiler. The cell-mediated immune response (LPR) increased significantly with the concentration of $\mathrm{Se}$ in broiler diet. Similar findings are also reported in domestic animals (Finch and Turner, 1996), humans (McKenzie et al., 1998) and broilers (Singh et al., 2006) fed diets with Se supplementation.

\section{Immune responses}

Selenium is an important for optimum immune response, and it influences the innate and acquired immune systems. Effect of dietary Se concentration on antibody titres to ND vaccine and lymphocyte proliferation ratio (LPR) in commercial broilers is presented in Table 4. Antibody titres against ND vaccine was not affected ( $p>0.05$ ) by feeding the diet containing varying concentration of $\mathrm{Se}$, which might be due to ideal ambient temperature during finisher phase. Contrary, in vitro cell-mediated immune response (LPR) increased linearly $(\mathrm{p}<0.001)$ with increasing the concentration of Se (up to $400 \mu \mathrm{g} / \mathrm{kg}$ ) in broiler diet. The immune modulator effect of $\mathrm{Se}$ might have mediated through reduction of stress in chicken as evident by increased antioxidant (GSH Px, GSH Rx, and RBCC) and decreased LP in the present study. Similarly, it has also been reported that Se or vitamin E greatly influences the humoral immune response up to 30 wks of age (Marsh et al., 1981), but not during the later phase in broilers. Similarly, Zhang et al. (2012) reported that the selenium supplementation in the chicken diets improved the immunological parameters.

Table 3. Stress parameters in broilers ( 6 wks of age) fed with different concentrations of Se in the diet

\begin{tabular}{llcccc}
\hline $\begin{array}{l}\text { Se } \\
(\mu \mathrm{g} / \mathrm{kg} \text { diet })\end{array}$ & HL ratio & $\begin{array}{c}\text { LP } \\
(\mathrm{nmol} \text { MDA/mg protein) }\end{array}$ & $\begin{array}{c}\text { RBCC } \\
\text { (units/g Hb) }\end{array}$ & $\begin{array}{c}\text { GSH Px } \\
\text { (units/ml) }\end{array}$ & $\begin{array}{c}\text { GSH Rx } \\
(\text { units/ml) }\end{array}$ \\
\hline 0 & 0.403 & 1.756 & 303.3 & 206.3 & 65.33 \\
100 & 0.355 & 1.630 & 353.1 & 230.7 & 71.26 \\
200 & 0.455 & 1.588 & 333.6 & 245.8 & 83.76 \\
300 & 0.419 & 1.435 & 370.1 & 260.3 & 82.20 \\
400 & 0.379 & 1.370 & 422.4 & 277.3 & 85.85 \\
SEM & 0.01 & 0.02 & 7.60 & 4.21 & 1.55 \\
p value & & & & 0.001 & 0.001 \\
$\quad$ Linear & 0.806 & 0.001 & 0.001 & 0.001 & 0.001 \\
$\quad$ Quadratic & 0.285 & 0.001 & & & \\
\hline
\end{tabular}

Each mean represents the data from eight chicks.

$\mathrm{GSH}=\mathrm{Px}$ glutathione peroxidase. $\mathrm{GSH}=\mathrm{Rx}$ glutathione reductase. $\mathrm{H}: \mathrm{L}=$ Heterophyl to lymphocyte $\mathrm{LP}=$ Lipid peroxidation. $\mathrm{RBCC}=\mathrm{RBC}$ catalase. $\mathrm{SEM}=$ Standard error mean . 
Table 4. Antibody titres to Newcastle disease vaccine and lymphocyte proliferation ratio in commercial broilers fed with different concentrations of Se in diet

\begin{tabular}{lcl}
\hline Se $(\mu \mathrm{g} / \mathrm{kg}$ diet $)$ & ND titre, ELISA & LPR \\
\hline 0 & 8,028 & 0.400 \\
100 & 6,484 & 0.489 \\
200 & 7,244 & 0.546 \\
300 & 7,389 & 0.564 \\
400 & 8,756 & 0.614 \\
SEM & 646 & 0.02 \\
p value & & \\
$\quad$ Linear & 0.61 & 0.001 \\
$\quad$ Quadratic & 0.57 & 0.001 \\
\hline
\end{tabular}

Each mean represents the data from eight chicks

ELISA $=$ Enzyme linked immunesorbent assay. LPR = Lymphocyte proliferation ratio. $\mathrm{ND}=$ Newcastle disease. $\mathrm{SEM}=$ Standard error mean .

Further, they reported that the deficiency in Se in the diets results in increased levels of oxidative stress and its related diseases. However, the lack of response in humoral immunity in the present study might be due to the study of the parameter was carried out at the latter phase of the broiler growth.

\section{CONCLUSIONS}

Based on the results, it is concluded that supplementation of Se did not influence body weight and feed efficiency. However, Se supplementation (up to 400 $\mu \mathrm{g} / \mathrm{kg}$ diet) increased anti-oxidant status (reduced LP and increased activities of GSH Px, GSH Rx, and RBCC) and LPR.

\section{REFERENCES}

Berg Meyer, H. U. 1983. Catalase. In: Methods of enzymatic analysis (Ed. H. U. Berg Meyer), vol 2. Verlag Chemie,Weinheim, pp. 165-166.

Bounous, D. I., R. P. Campagnoli and J. Brown. 1992. Comparison of MTT colorimetric assay and tritiated thymidine uptake for lymphocyte proliferation assays using chicken splenocytes. Avian Dis. 36:1022-1027.

Cave, A. C., A. C. Brewer, A. Narayanapanicker, R. Ray and D. J. Grieve. 2006. NADPH oxidases in cardiovascular health and disease. Antioxid. Redox Signal. 8:691-728.

Choct, M., A. J. Naylor and N. Reinke. 2004. Selenium supplementation affects broiler growth performance, meat yield and feather coverage. Br. Poult. Sci. 45:677-683.

Christine, A. Z., R. E. Messikommer and W. Caspar. 2002. Choice feeding of selenium-deficient laying hens affects diet selection, selenium intake and body weight. J. Nutr. 132:3411-3417.

Cohen, G., D. Dembiec and J. Marcus. 1970. Measurement of catalase in tissue extract. Anal Biochem. 34:30-38.

Devi, G. S., M. H. Prasad, I. Saraswathi, D. Raghu and D. N. Rao. 2000. Free radicals antioxidant enzymes and lipid peroxidation in different types of leukemias. Clin. Chim. Acta 293:53-62.

Downs, K. M., J. B. Hess and S. F. Bilgili. 2000. Selenium source effect on broiler carcass characteristics, meat quality, and drip loss. J. Appl. Anim. Res. 18:61-72.

Finch, J. M. and R. J. Turner. 1996. Effects of selenium and vitamin $\mathrm{E}$ on the immune responses of domestic animals. Res. Vet. Sci. 60:97-106.

Fridivich, I. 1978. The biology of oxygen radicals. Science 20:87.

Georgieva, N. V., K. Stoyanchev, N. Bozakova and I. Jotova. 2011. Combined effects of muscular dystrophy, ecological stress, and selenium on blood antioxidant status in broiler chickens. Biol. Trace Elem. Res. 142:532-545.

Hegazy, S. M. and Y. Adachi. 2000. Comparison of the effects of dietary selenium, zinc, and selenium and zinc supplementation on growth and immune response between chick groups that were inoculated with Salmonella and aflatoxin or Salmonella. Poult. Sci. 79:331-335.

Hoffmann, P. R. 2007. Mechanisms by which selenium influences immune responses. Arch. Immunol. Ther. Exp. 55:289-297.

Ibrahim, M. T., B. H. Eljack and I. M. T. Fadlalla. 2011. Selenium supplementation to broiler diets. Anim. Sci. J. 2:12-17.

Koski, K. G. and E. Marilyn. 2003. Gastrointestinal nematodes, trace elements, and immunity. J. Trace Elem. Exp. Med. 16:237-251.

Krstic, B., Z. Jokić, Z. Pavlović and D. Zivković. 2012. Options for the production of selenized chicken meat. Biol. Trace Elem. Res. 146:68-72.

Kuhn, H. and A. Borchert. 2002. Regulation of enzymatic lipid peroxidation: the interplay of peroxidizing and peroxide reducing enzymes. Free Radic. Biol. Med. 33:154-172.

Lesson, S. and J. D. Summer. 2001. Nutrition of chickens. 4th edn. University book, Guelph, Ontario, Canada. N1H6N8.

Llames, C. and Y. Fontaine. 1994. Determination of amino acids in feeds: collaborative study. J. AOAC Int. 77:1262-1402.

Marsh, J. A., R. R. Dietert and G. F. Combs. 1981. Influence of dietary selenium and vitamin $\mathrm{E}$ on the humoral immune response of the chick. Proceedings of the Society for Experimental Biology and Medicine 166:228-236.

McKenzie, R. C., T. S. Rafferty and G. J. Beckett. 1998. Selenium: an essential element for immune function. Immunol. Today 19: 342-345.

Niu, Z. Y., F. Z. Liu, Q. L. Yan and W. C. Li. 2009. Effects of different levels of vitamin $\mathrm{E}$ on growth performance and immune responses of broilers under heat stress. Poult. Sci. 88:2101-2107.

Nunes, A. V., A. J. Gozzo, I. Crus-Silva, M. A. Juliano and T. A. Viel. 2005. Vitamin E prevents cell death induced by mild oxidative stress in chicken skeletal muscle cells. Comp. Biochem. Physiol. C Toxicol. Pharmacol. 141:225-240.

Ohkawa, Y., N. Ohishi and K. Yagi. 1979. Assay for lipid peroxides in animal tissue by thiobarbituric acid reaction. Anal. Biochem. 95:351-358.

Paglia, D. E. and W. N. Valantine. 1967. Studies on quantitative characterization of erythrocytes glutathione peroxidase. J. Lab. Clin. Med. 79:158-169.

Panda, A. K., S. V. Ramarao, M. V. L. N. Raju and R. N. Chatterjee. 2008. Effect of dietary supplementation with vitamins $\mathrm{E}$ and $\mathrm{C}$ on production performance, immune responses and antioxidant status of White Leghorn layers 
under tropical summer conditions. Br. Poult. Sci. 49:592-599.

Papp, L. V., J. Lu and A. Holmgren. 2007. From selenium to selenoproteins: synthesis, identity, and their role in human health. Antioxid. Redox. Signal. 9:775-806.

Payne, R. L. and L. L. Southern. 2005. Comparison of inorganic and organicselenium sources for broiler. J. Poult. Sci. 84:898902.

Perić, L., N. Milošević, D. Žikić, Z. Kanački, N. Džinić, L. Nollet and P. Spring. 2009. Effect of selenium sources on performance and meat characteristics of broiler chickens. J. Appl. Poult. Res. 18:403-409.

Sahin, K. and O. Kucuk. 2003. Heat stress and dietary vitamin supplementation of poultry diets. Nutrition Abstracts and Reviews, Series B, 73:41R-50R.

Singh, H., S. Sodhi and R. Kaur. 2006. Effects of dietary supplements of selenium, vitamin $\mathrm{E}$ or combinations of the two on antibody responses of broilers. Br. Poult. Sci. 47:714719.
Spallholz, J. E., J. L. Martin, M. L. Gerlach and R. H. Heinzerling. 1973. Enhanced immunoglobulin M and immunoglobulin G antibody titers in mice fed selenium. Infect. Immun. 8:841-842.

Tappel, A. and A. Tappel. 2004. Oxidant free radical initiated chain polymerization of protein and other biomolecules and its relationship to diseases. Med. Hypothese 63:98-99.

Thompson, J. N. and M. L. Scott. 1970. Impaired lipid and vitamin E absorption related to atrophy of the pancreas in seleniumdeficient chicks. J. Nutr. 100:797-809.

Toghyani, M., A. Khodami and A. A. Gheisari. 2008. Effect of organic chromium supplementation on meat quality of heat stressed broiler chicken. Am. J. Anim. Sci. 3:62-67.

Wiseman, H. and B. Halliwell. 1996. Damage to DNA by reactive oxygen and nitrogen species: role in inflammatory disease and progression to cancer. Biochem. J. 313:17-29.

Zhang, Z. W., Q. H. Wang, J. L. Zhang, S. Li, X. L. Wang and S. W. Xu. 2012. Effects of oxidative stress on immunosuppression induced by selenium deficiency in chickens. DOI 10.1007/s12011-012-9439-0. 